\title{
Process Intensification in Tiopronin Extraction
}

\author{
Zhigang Tang, Zhimin He, Hongwei Li, Dong Guo, and Zhijun Zhao
}

\begin{abstract}
In order to reduce the loss of ethyl acetate during tiopronin extraction, counter-current extraction is presented to replace the conventional cross-current extraction, as a process intensification strategy. Firstly the distribution coefficient of tiopronin between ethyl acetate and aqueous phase is determined. Next a calculation of counter-current extraction is done based on Matlab procedure. By the results, to achieve the effect of current production, it will save more than $60 \%$ extractant dosage by making use of 3-stage counter-current extraction. Moreover the conversion degree will increase three times replacing cross-current extraction by counter-current extraction.
\end{abstract}

Index Terms-Tiopronin, ethyl acetate, extraction, process intensification, conversion degree.

\section{INTRODUCTION}

Tiopronin (TPN), N-(2-thiol propionyl)-gly, CAS No 1953-02-2, is a new free thiol-containing glycine derivative. It can protect the liver tissue, improve liver function cells, repair ethanol-induced liver injury repair [1]-[7]. Schematic diagram of TPN industrial synthesis is shown as Fig. 1. Crude TPN got by reactions is then extracted by ethyl acetate (EA) from aqueous solution, evaporated and concentrated next. Finally, after crystallization and dry the product TPN is obtained.

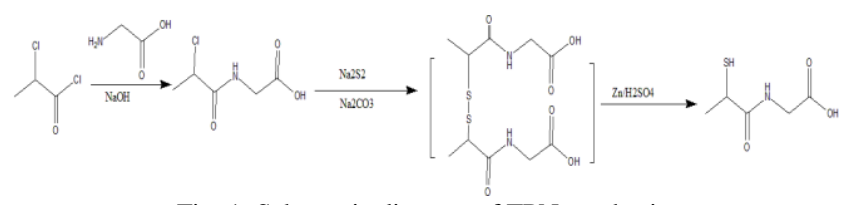

Fig. 1. Schematic diagram of TPN synthesis.

TPN is generally extracted by EA through 3-stage cross-current extraction. The fundamental process is as follows: 800 900 kg TPN aqueous solution (containing TPN 70 80kg) is put into the extraction tank 1 and mixed with $370 \sim 430 \mathrm{~kg}$ EA at $151 \sim 20^{\circ} \mathrm{C}$. Stirring for $30 \mathrm{~min}$, mixture is settled and extract raffinate phase is separated from the extract phase. The raffinate from tank 1 is next mixed with 370 430kg EA in extraction tank 2 under the same conditions as in tank1 for $30 \mathrm{~min}$. After clarification and phase separation, the raffinate from tank 2 is extracted repeatedly in tank 3 similar to tank 2 and tank1. Extract phase from tank1, 2, and 3 is collected to produce the TPN product after evaporation and crystallization.

The most serious problem puzzled this process is large loss of EA. According to factual data from workshop, the

Manuscript received January 27, 2016; revised August 6, 2016.

Zhigang Tang, Zhimin He, Hongwei Li, Dong Guo, and Zhijun Zhao are with State Key Laboratory of Chemical Engineering, Chemical Engineering Department, Tsinghua University, Beijing 100084 China (e-mail: zhg-tang@mail.tsinghua.edu.cn, thaaam@yeah.net, lihw12@qq.com, studing@sina.com,zhaozj@mail.tsinghua.edu.cn). loss of EA is over than $30 \%$.

After a primary analysis, except evaporative loss related to EA recovery, the important reason lead to large loss of EA is a large amount of EA used in low-efficiency cross-current extraction.

In this paper, counter-current extraction is presented to replace the existed cross-current extraction, in order to intensify the extraction of TPN, increase the conversion degree, reduce the amount of extractant and cut down the loss of EA.

\section{EXPERIMENTAL}

In order to compare the result of cross-current extraction with that of counter-current extraction, it needs to determine the distribution coefficient of TPN between organic phase and aqueous phase by experiments.

\section{A. Materials}

TPN (with purity of TPN $\geq 99 \%$ ), TPN feed (aqueous solution, with conc. of TPN 10 20g/L), EA reagent (with analytic purity of EA $\geq 99.9 \%$ ), EA extractant (with industrial purity of EA $\geq 99 \%$ ), all is supplied by CONGQING KANGLE Pharmaceutical Co., China.

\section{B. Procedures}

(a) $1 \sim 10 \mathrm{~g}$ TPN is dissolved separately in $1000 \mathrm{ml}$ deionized water to prepare TPN aqueous solution with different concentration. TPN aqueous solution is mixed with EA reagent at different volume ratio, stirred for $30 \mathrm{~min}$ in a conical flask at room temperature. After phase separation, extract phase and raffinate phase is analyzed by HPLC and conc. of TPN in two phases is determined. Then distribution coefficient of TPN is calculated;

(b) TPN feed is firstly pre-treated by filtration to remove suspended solid, then is mixed with EA extractant at different volume ratio, stirred for $1 \mathrm{hr}$ in a conical flask at room temperature. After phase separation, extract phase and raffinate phase is analyzed by HPLC and conc. of TPN in two phases is determined. Distribution coefficient of TPN is then calculated.

\section{Analysis Method}

Conc. of TPN is determined by Shimazu reverse HPLC [8]-[10], Ø4.6 $\mathrm{mm} \times 150 \mathrm{~mm} \mathrm{C18}$ column is used ( stationary phase: Phenomenex Aqua, $5 \mu \mathrm{m}$ ) $\circ$ Gradient elution is applied using mixture of A $(2.3 \mathrm{~g} / \mathrm{L}$ phosphoric acid aqueous solution) with methanol at flow rate of 1.0 $\mathrm{mL} / \mathrm{min}$. Analysis conditions is as bellow: detecting wavelength $210 \mathrm{~nm}$, temperature of column $40^{\circ} \mathrm{C}$, injection volume $20 \mu \mathrm{L}$.

Concentration of TPN is aqueous phase and organic phase is calculated using external standard method, according to the following formula: 


$$
c_{X}=\frac{c_{R} \cdot A_{X}}{A_{R}}
$$

where: $c_{R}$-concentration reference substance (TPN with high purity of $99.9 \%), \mathrm{g} / \mathrm{L} ; A_{R}$ - peak area of conference substance; $c_{X}$-concentration of sample, g/L; $A_{X}$ - peak area of sample.

\section{CAlculation}

A. Extracting Effect of Cross-Current Extraction vs. that of Counter-Current Extraction

Applied the fundamental calculation methods of cross-current extraction and counter-current extraction [11] and Introduced the distribution coefficient from experimental, it is programmed and solved based on MATLAB. During the calculation, it is assumed EA and water is immiscible.

\section{B. Conversion Degree of Cross-Current Extraction and Counter-Current Extraction}

To further compare the difference between the efficiency of cross-current extraction and that of counter-current extraction in time and in space, conversion degree [12], revealing the efficiency of mass transfer unit in time and in space, is introduced to evaluate the performance of cross-current extraction and counter-current extraction.

\section{RESUlTS AND DisCUSSION}

\section{A. Determination of Distribution Coefficient}

TPN is dissolved in water to prepare the TPN aqueous solution with a concentration of $1 \sim 10 \mathrm{~g} / \mathrm{L}$. Then EA is used to extract TPN from the above aqueous solution to determine the distribution coefficient of TPN between two phases. The experimental results are shown in Table I.

TABLE I: DISTRIBUTION COEFFICIENT OF TPN AT $26.4^{\circ} \mathrm{C}$

\begin{tabular}{llll}
\hline \hline Phase ratio(volume) & $2: 1$ & $1: 1$ & $0.5: 1$ \\
\hline Extracting 1 times & 1.87 & 1.81 & 1.92 \\
Extracting 2 times & 2.11 & 2.10 & 1.84 \\
Extracting 3 times & 1.77 & 2.13 & 1.97 \\
Average value & 1.92 & 2.01 & 1.91 \\
\hline \hline
\end{tabular}

Note: Data are from the extraction of TPN aqueous solution prepared by TPN dissolving in deionized water using EA reagent.

TABLE II: (A) DISTRIBUTION COEFFICIENT OF TPN AT $26.6^{\circ} \mathrm{C}$ BETWEEN RAFFINATE AND EXTRACT AFTER 1ST EXTRACTION

\begin{tabular}{lll}
\hline \hline parameters & $\begin{array}{l}\text { Raffinate after 1st } \\
\text { extraction }\end{array}$ & $\begin{array}{l}\text { Extract after 1st } \\
\text { extraction }\end{array}$ \\
\hline volume/mL & 48.30 & 41.00 \\
weight/g & 58.80 & 34.60 \\
Conc. of sample1 (g/L) & 12.69 & 22.31 \\
Conc. of sample1 (g/L) & 12.48 & 21.94 \\
Ave. Conc. (g/L) & 12.59 & 22.13 \\
Distribution coefficient & \multicolumn{2}{|c}{1.76} \\
\hline \hline
\end{tabular}

As what we have seen, distribution coefficient of TPN, determined under experimental conditions as listed in section II, according to method (a) in B procedures, using EA reagent, from the extraction of TPN aqueous solution prepared by TPN dissolving in deionized water, nearly equals to constant, between 1.91 2.01.

According to method (b) in B procedures, TPN feed is firstly pre-treated by filtration to remove suspended solid, then is mixed with EA extractant. Distribution coefficient of TPN determined by experiments is shown in Table II.

TABLE II: (B) DISTRIBUTION COEFFICIENT OF TPN AT $26.6^{\circ} \mathrm{C}$ BETWEEN

\begin{tabular}{lll}
\multicolumn{2}{c}{ RAFFINATE AND EXTRACT AFTER 2ND EXTRACTION } \\
\hline \hline parameters & $\begin{array}{l}\text { Raffinate after 2st } \\
\text { extraction }\end{array}$ & $\begin{array}{l}\text { Extract after 2st } \\
\text { extraction }\end{array}$ \\
\hline volume/mL & 44.60 & 40.40 \\
weight/g & 47.10 & 35.80 \\
Conc. of sample1 (g/L) & 7.10 & 12.56 \\
Conc. of sample1 (g/L) & 6.98 & 12.35 \\
Ave. Conc. $(\mathrm{g} / \mathrm{L})$ & 7.04 & 12.46 \\
Distribution coefficient & \multicolumn{2}{c}{1.77} \\
\hline \hline
\end{tabular}

TABLE II: (C) DISTRIBUTION COEFFICIENT OF TPN AT $26.6^{\circ} \mathrm{C}$ BETWEEN RAFFINATE AND EXTRACT AFTER 3RD EXTRACTION

\begin{tabular}{lll}
\hline \hline parameters & $\begin{array}{l}\text { Raffinate after 3st } \\
\text { extraction }\end{array}$ & $\begin{array}{l}\text { Extract after 3st } \\
\text { extraction }\end{array}$ \\
\hline volume/mL & 42.10 & 40.20 \\
weight/g & 50.60 & 35.10 \\
Conc. of sample1 (g/L) & 4.35 & 7.78 \\
Conc. of sample1 (g/L) & 4.28 & 7.65 \\
Ave. Conc. (g/L) & 4.32 & 7.72 \\
Distribution coefficient & \multicolumn{2}{|l}{1.79} \\
Ave. distribution & & 1.77 \\
coefficient & &
\end{tabular}

Note: 1.Data are from the extraction of TPN feed by EA extractant; 2.Ave conc. of TPN feed is $16.84 \mathrm{~g} / \mathrm{L} ; 3$ Phase ratio (volume of TPN feed vs EA extractant ) in extraction is $50: 40$.

As shown in Table II, distribution coefficient of TPN, determined under experimental conditions, according to method (b) in procedures B, from the extraction of TPN feed, also nearly equals to constant, between 1.76 1.79. But it is smaller than that from the extraction of TPN aqueous solution prepared by TPN dissolving in deionized water using EA reagent.

By primary analysis, decrease of distribution coefficient of TPN may be due to the impurities containing in TPN feed produced from synthesis of TPN. In industrial production, EA extractant is recovered and re-used repeatedly. This may lead to reduction of EA content in extractant and affect on extraction of TPN.

\section{A. Calculation of Cross-Current Extraction and Counter-Current Extraction}

Using MATLAB programming, calculation is done to simulate the multi-stage cross-current extraction and multi-stage counter-current extraction by experimental results. In calculation, coefficient of TPN between two phase is taken as 1.77. The concentration of TPN in feed and feed throughput is $13.5 \mathrm{~g} / \mathrm{L}$ and $900 \mathrm{~kg} / \mathrm{d}$, separately. According to factual production parameters, $1140 \mathrm{~kg} \mathrm{EA}$ extractant was used evenly in 3-stage cross-current extraction, finally the concentration of TPN raffinate is about 3.4 g/L. Fig. 2 shows the change of concentration of 
TPN in raffinate with the extraction stages in cross-current extraction and counter-current extraction, to reach the same TPN concentration in $3^{\text {rd }}$ raffinate phase.

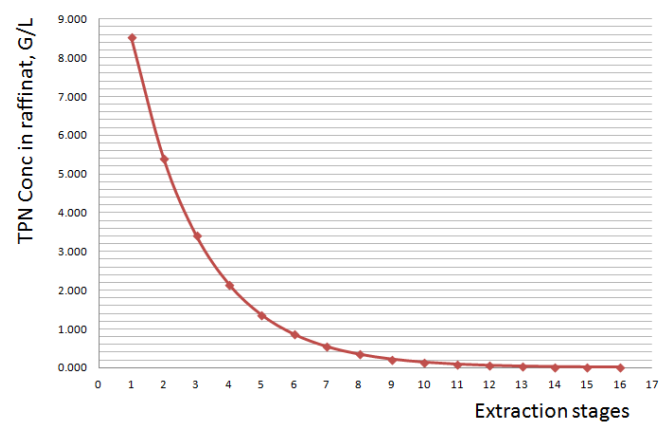

(a) In cross-current extraction with EA eatractant amount of $1140 \mathrm{~kg}$.

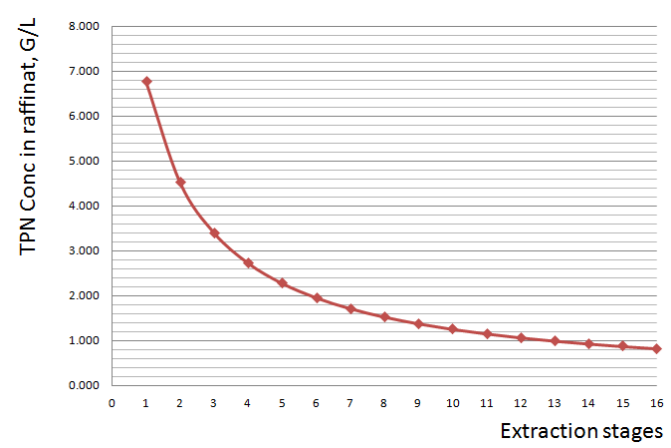

(b) In counter-current extraction with EA extractant amount of $450 \mathrm{~kg}$

Fig. 2. Change of TPN concentration in raffinate with the extraction stages in cross-current extraction and in counter-current extraction.

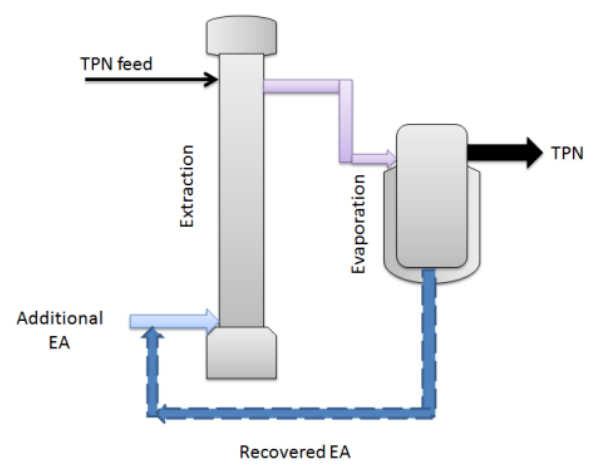

(a) counter-current extraction

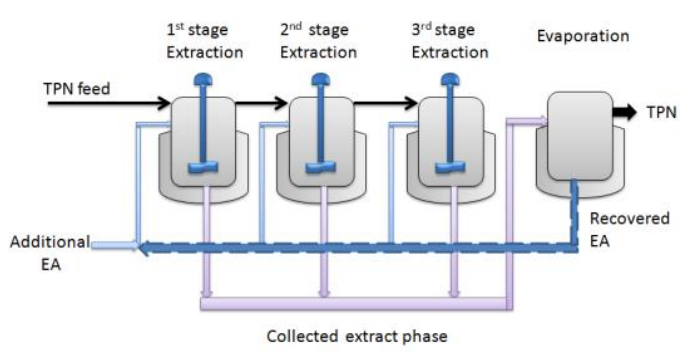

(b) cross-current extraction

Fig. 3. Schematic diagrams of counter-current extraction process and cross-current extraction process.

By the result, to reach the same TPN concentration 3.4 $\mathrm{g} / \mathrm{L}$ in $3^{\text {rd }}$ raffinate phase, equivalent to TPN recovery yield of $74.81 \%$, it needs EA extractant $1140 \mathrm{~kg}$ in cross-current extraction but only $500 \mathrm{~kg}$ in counter-current extraction, all after 3-stage extraction. EA extractant can be saved more than by $60 \%$. Moreover, if EA extractant amount is increased to $750 \mathrm{~kg}$, TPN concentration in raffinate will decrease to $1.35 \mathrm{~g} / \mathrm{L}$ and TPN recovery yield is increased to
$90 \%$.

\section{B. Conversion Degree of Cross-Current Extraction and Counter-Current Extraction}

Counter-current extraction not only cuts down the amount and los of EA extractant but also simplifies the process, as shown in Fig. 3.

Moreover, counter-current can reduce the consumption, as shown in Table III.

TABLE III: DEVICE PARAMETERS AND CONSUMPTIONS FOR CROSS-CURRENT AND COUNTER-CURRENT EXTRACTION

\begin{tabular}{lcc}
\multicolumn{1}{c}{ Method } & $\begin{array}{c}\text { Cross-current } \\
\text { extraction }\end{array}$ & $\begin{array}{c}\text { Counter-current } \\
\text { extraction }\end{array}$ \\
\hline Recovered TPN & $\begin{array}{c}\text { (1) Extraction parameters } \\
\text { Average } 75 \mathrm{~kg} / \mathrm{d}\end{array}$ & Average $75 \mathrm{~kg} / \mathrm{d}$ \\
Total amount of EA & $1140 \mathrm{~kg} / \mathrm{d}$ & $500 \mathrm{~kg} / \mathrm{d}$ \\
extractant & (2) Device parameters & \\
& $3 \mathrm{~m} 3 \times 3$ & $\varnothing 200 \times 4500$ \\
Extracting device & $3 \mathrm{~m} 3$ & $3 \mathrm{~m} 3$ \\
Evaporating device & (3) Consumptions & \\
Loss of EA extractant & $228 \mathrm{~kg} / \mathrm{d}$ & $160 \mathrm{~kg} / \mathrm{d}$ \\
Electricity & $30 \mathrm{kw}$ & $10 \mathrm{kw}$ \\
Steam & $0.74 \mathrm{t} / \mathrm{d}$ & $0.52 \mathrm{t} / \mathrm{d}$ \\
\hline
\end{tabular}

In further illustrating the advantages of counter-current extraction in terms of space efficiency and time efficiency, a parameter of conversion degree [12] is introduced and calculated. Conversion degree is defined as the product yield within unit space volume, unit time and unit energy consumption. Authors have applied conversion degree to analyze the performance of several de-benzene process, such as double furnace-double column process, double furnace-single column process, single furnace-double column, single furnace-single column, respectively and achieved a good result.

According to Table III and definition the conversion degree of cross-current and counter-current is calculated as the following,

$$
\begin{aligned}
& \text { conversion } \cdot \operatorname{deg} \mathrm{ree} \cdot \text { of } \cdot \text { cross }- \text { current } \cdot \text { extraction }= \\
& \frac{75 \mathrm{~kg} / \mathrm{d} T P N}{12 \mathrm{~m}^{3} \times(26.6+0.44+0.026) \mathrm{Mkcal} / \mathrm{d}}=0.23 \mathrm{kgTPN} /\left(\mathrm{m}^{3} \cdot \mathrm{Mkcal}\right)
\end{aligned}
$$

conversion $\cdot \operatorname{deg}$ ree $\cdot$ of $\cdot$ counter - current $\cdot$ extraction $=$ $\frac{75 \mathrm{~kg} / \mathrm{d} T P N}{(0.18+3) \mathrm{m}^{3} \times(21.3+0.27+0.008) \mathrm{Mkcal} / \mathrm{d}}=1.01 \mathrm{kgTPN} /\left(\mathrm{m}^{3} \cdot \mathrm{Mkcal}\right)$

As can be seen, the conversion degree will increase dramatically when cross-current extraction is replaced by counter-current extraction.

\section{CONCLUSions}

During the experimental research range, distribution coefficient of TPN nearly equals to constant, between 1.91 2.01, when TPN aqueous solution prepared by TPN dissolving in deionized water is extracted by EA reagent; It also nearly equals to constant, between 1.76 1.79, when TPN feed is extracted by EA extractant. By MATLAB 
programming and calculating, to reach the same TPN concentration $3.4 \mathrm{~g} / \mathrm{L}$ in final raffinate phase, after 3 -stage cross-current extraction and 3-stage counter-current extraction, the later can save EA extractant in amount more than $60 \%$ and When cross-current extraction is replaced by counter-current extraction, The conversion degree will increase by more than three times.

In further study, trial experiments will carry out to verify the performance of counter-current extraction of TPN.

\section{REFERENCES}

[1] H. C. Dai, P. Shu, and Z. P. Xiong, "Synthesis of Tiopronin," Chinese Journal of Pharmaceuticals, vol. 24, no. 6, pp. 243, 1993.

[2] Y. C. Luo, H Zhang, Y. H. Yang, X. L. Zhang, and J. S. Yang, "An improvement preparation of tiopronin," Fine Chemical Intermediates, vol. 37, no. 5, pp. 43-45, 2007.

[3] D. Y. Wang, C. Z. Zhang, J. Liu, and W. H. Shi, "A new synthesis of Tiopronin," Chinese Journal of Medicinal Chemistry, vol. 7 no. 1, pp. 55-57, 1997.

[4] X. P. Li and F. Wen, "The role of tiopronin for the prevention of chemotherapy-related liver toxicity in advanced colorectal cancer patients treated with mFOLFOX7: A prospective analysis," TUMORI, vol. 100, pp. 446-451, 2014.

[5] M. C. Tang, L Cheng, L Qiu, R. G. Jia, R. Q. Sun, X. P. Wang, G. Y. $\mathrm{Hu}$, and Y. Zhao, "Efficacy of Tiopronin in treatment of severe non-alcoholic fatty liver disease," European Review for Medical and Pharmacological Sciences, vol. 18, no. 2, pp. 160-164, January 2014.

[6] B. Zhang, X. B. Liu, and X. A. Ling, "Preventive effects of tiopronin on cushings ulcer in rats with craniocerebral injury," China Pharmacy, vol. 24, no. 21, pp. 1960-1963, 2013.

[7] K. Valachova, M. Banasova, D. Topol'ska, V. Sasinkova, I. Juranek, M. N. Collins, and L. Soltes, "Influence of tiopronin, captopril and levamisole therapeutics on the oxidative degradation of hyaluronan," Carbohydrate Polymers, vol. 134, pp. 516-523, 2015.

[8] J. Huang, Y. J. Yin, H. W. Huang, Q. M. Zhang, and T. J. Hang, "Determination of tiopronin injection and its related substances in tiopronin injection by HPLC," Chinese Pharmaceutical Journal, vol. 44, no. 14, pp. 1108-1111, 2009.

[9] J. G. Lu, L. Y. Wang, L. Pei et al., "HPLC determination by gradient elutionof related substances in tiopronin injection," Chinese Journal Pharmaceutical Analasis, vol. 31, no. 3, pp. 499-503, 2011.

[10] E. Hao, Y. Liu, G. Q. Xu et al., "Determination of Plasma Tiopronin Concentration by HPLC," Journal of Henan Normal University. Natural Science, vol. 39. no. 4, pp. 102-104, 2011.

[11] W. J. Jiang, Chemical Engineering Principles. Beijing: Publishing House of Tsinghua University, 2010.

[12] Z. G. Tang, Y. M. Wen, D. F. Wang et al., "Evaluation of negative pressure debenzolization process and their conversion degrees," Coal Chemical Industry, vol. 43, no. 5, pp. 47-50, 2015.

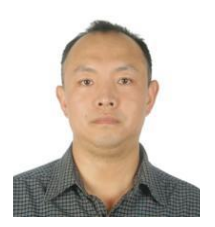

Zhi-Gang Tang was born in Lanzhou City, Gansu Province, China, on April 1, 1970. He got his bachelor degree at Chemical Engineering Department, Tsinghua University, Beijing, in June 1993. He got his Ph.D. at Chemical Engineering Department, Tsinghua University, Beijing, in April 1998. In 1998, he was hired as a lecturer of Chemical Engineering
Department, Tsinghua University, Beijing. In 2000 (to now), he was hired as Associate Professor of State Key Laboratory of Chemical Engineering, Chemical Engineering Department, Tsinghua University, Beijing. He teaches two graduate-oriented courses "Fundamental in Separation Process" and "Generality of low-carbon process". His current research interests cover 1) Fundamental and application of identified methods in vapor-liquid mass transfer; 2) Process and equipments in clear and low-carbon industrial production; 3) Trapping $\mathrm{CO}_{2}$ from syngas by hybrid technology

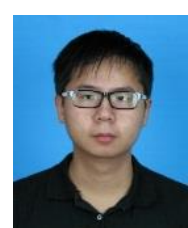

Zhimin He was born in Yiyang, Hunan Province, Chinese on October 7, 1991, he got bachelor's degree in Beijing in August 2014 from Tsinghua University, Department of chemical engineering. His current research interests include 1) How to make the membrane with high-throughput and high-enriched factor; 2) clear,low carbon industrial production process.

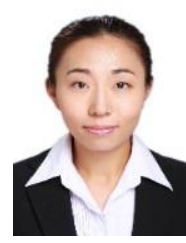

Hongwei Li was born in Dezhou City, Shandong Province, China, on May 5, 1989. She got her bachelor degree at the Department of Environmental Engineering, North China Institute of Science and Technology, Hebei, in June 2012. She is a third year master at Chemical Engineering Department, Tsinghua University, Beijing. Her paper project is $\mathrm{CO}_{2}$ absorption by physical solvent and $\mathrm{CO}_{2}$ capture from syngas by cryogenic distillation.

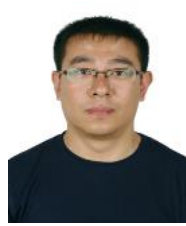

Dong Guo was born in Jinzhong Shanxi Shanxi Province, Chinese on May 25, 1978 he got engineer title in Beijing in August 2005. In 2000, he was hired to assist Tang Zhigang, associate professor of Tsinghua University, Department of Chemical Engineering. His current research interests include 1) principle and the application in the identification method of gas liquid mass transfer; 2) clear, low carbon industrial production process and equipment.

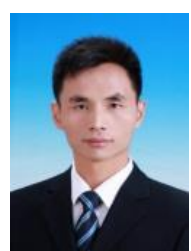

Zhi-Jun Zhao was born in Shijiazhuang city, Hebei Province, China, on October 28, 1980. He got his master degree on Chemical Engineering Department, Tianjin University, Tianjin, in June of 2008. In 2010, He was hired as Assistant Professor of China Institute of Atomic Energy, China National Nuclear Corporation, Beijing. $\mathrm{He}$ got his Ph.D. at Institute of Process Engineering, Chinese academy of Science, Beijing, in June of 2014. In September of 2014 (to now), he was hired as post-doctor of Chemical Engineering Department, Tsinghua University, Beijing. His current research interests cover 1) Molecular Simulations and properties, preparation and application of ionic liquids; 2$)$ Capturing acid gases $\left(\mathrm{CO}_{2}\right.$ $\mathrm{H}_{2} \mathrm{~S}$ and $\mathrm{SO}_{2}$ ) from flue gas or syngas by green solvent 